\title{
A AVALIAÇÃo COMO PRÁTICA FUNDAMENTAL PARA A APRENDIZAGEM EFETIVA
}

\author{
EVALUATION AS A FUNDAMENTAL PRACTICE FOR EFFECTIVE LEARNING
}

LA EVALUACIÓN COMO PRÁCTICA FUNDAMENTAL PARA EL APRENDIZAJE EFECTIVO

\section{Fernanda Luzia de Almeida Miranda (iD) 9}

Mestrado em Ensino (Univates)

Técnica em Assuntos Educacionais no Instituto Federal de Mato

Grosso (IFMT), Campus Barra do

Garças

flamirandabg@hotmail.com

\section{Jacqueline Silva da Silva (iD) 9}

Doutorado em Educação (UFRGS)

Professora Titular da Universidade do Vale do Taquari (Univates)

Docente dos Programas de Pósgraduação em Ensino e em Ensino de Ciências Exatas

jacqueh@univates.br

\section{Marli Teresinha Quartieri (iD) 9}

Doutorado em Educação pela Universidade Vale do Rio dos Sinos - RS

Professora titular da Universidade do Vale do Taquari (Univates) Docente dos Programas de Pósgraduação em Ensino e em Ensino de Ciências Exatas mtquartieri@univates.br

\begin{abstract}
Resumo
Este artigo tem por objetivo promover uma reflexão sobre a avaliação escolar, discutindo sobre como ela poderia passar a ser uma prática focada na aprendizagem efetiva dos alunos. Trata-se de um estudo de caso, com abordagem qualitativa, que se baseou em autores como Gil (2018), Luckesi (2010, 2011, 2013) e Hoffmann (2011) e em dados que foram obtidos a partir de uma entrevista semiestruturada com quatro educadores de Barra do Garças-MT, analisados sob a ótica da análise de conteúdo, segundo Bardin (2011). Como principal resultado deste estudo, pôde-se compreender que o demasiado enfoque na obtenção de notas tem sido motivo relevante para a avaliação ser vista como causadora de temor e ansiedade em muitos estudantes, tornandose essencial sua transformação em prática focada na aprendizagem, o que requer que seja entendida como atividade contínua, inclusiva, flexível e instigadora de reflexão sobre o processo educativo.
\end{abstract}

Palavras-chave: Avaliação. Processo Educativo. Aprendizagem Efetiva.

Recebido em: 9 de novembro de 2021 .

Aprovado em: 11 de janeiro de 2022.

Como citar esse artigo (ABNT):

MIRANDA, Fernanda Luzia de Almeida; SILVA, Jacqueline Silva da; QUARTIERI, Marli Teresinha. A avaliação como prática fundamental para a aprendizagem efetiva. Revista Prática Docente, v. 7, n. 1, e004, 2022. http://doi.org/10.23926/RPD.2022.v7.n1.004.id1353 


\begin{abstract}
This article aims to promote a reflection on school evaluation, discussing how it could stop being an instrument focused on results and becoming a practice focused on the effective learning of students. This is a case study with a qualitative approach, based on authors such as Gil (2018), Luckesi (2010, 2011, 2013) and Hoffmann (2011) and on data obtained from a semistructured interview with four educators from Barra do GarçasMT, analyzed from the perspective of content analysis, according to Bardin (2011). As the main result of this study, it could be understood that the excessive focus on obtaining grades has been the relevant reason for an assessment to be seen as causing fear and anxiety in many students, making its transformation into a practice focused on learning essential, which demands that it be understood as a continuous, inclusive, flexible activity and that encourages a reflection on the educational process.
\end{abstract}

Keywords: Evaluation. Educational Process. Effective Learning.

\section{Resumen}

Este artículo tiene como objetivo promover una reflexión sobre la evaluación escolar, discutiendo cómo podría convertirse en una práctica enfocada en el aprendizaje efectivo de los estudiantes. Se trata de un estudio de caso, con un enfoque cualitativo, que se basó en autores como Gil (2018), Luckesi (2010, 2011, 2013) y Hoffmann (2011) y en datos recolectados de una entrevista semiestructurada a cuatro educadores de Barra do Garças-MT, analizados bajo la óptica del análisis de contenido, según Bardin (2011). Como resultado principal de este estudio, se pudo comprender que el excesivo enfoque en la obtención de calificaciones ha sido un motivo relevante que la evaluación sea vista como causante de miedo y ansiedad en muchos estudiantes, haciendo imprescindible su transformación en práctica centrada en el aprendizaje, lo que requiere que se entienda como una actividad continua, inclusiva, flexible e incitante a la reflexión sobre el proceso educativo.

Palabras clave: Evaluación. Proceso educativo. Aprendizaje efectivo. 


\section{INTRODUÇÃO}

A avaliação é uma prática frequente em nosso cotidiano e sua aplicação não se restringe à vida escolar. Somos avaliados em diferentes momentos e espaços de nossa existência, embora nem sempre isso ocorra de forma consciente e sistemática.

Contudo, não nos interessa fazer uma abordagem ampla de avaliação, mas tratá-la como elemento essencial do processo educativo. Portanto, este estudo tem o objetivo de promover uma reflexão sobre a avaliação escolar, discutindo como ela pode se tornar uma prática centrada na aprendizagem efetiva dos alunos, superando o modelo avaliativo por muito tempo preponderante no cotidiano escolar: rígido, excludente, focado em resultados e causador de sofrimento a muitos estudantes.

Buscando atender ao objetivo proposto, foram realizadas entrevistas com quatro educadores do município de Barra do Garças - MT, sendo-lhes questionados: os possíveis motivos de a avaliação ter provocado temor e ansiedade em muitos alunos ao longo de sua vida escolar; os modos como se pode superar a concepção de avaliação como instrumento mensurador de resultados e causadora de sofrimento nos estudantes; e quais características são necessárias para que ela se torne prática educativa viabilizadora de melhorias nos processos de ensino e de aprendizagem.

Em suma, este artigo apresenta uma breve introdução, uma revisão bibliográfica baseada em autores como Gil (2018), Luckesi (2010, 2011 e 2013) e Hoffmann (2011) e, por fim, uma análise qualitativa dos recortes discursivos dos professores obtidos a partir das entrevistas semiestruturadas, respaldada nos pressupostos teóricos do presente estudo.

\section{AVAliaÇão ESCOLAR: DE INSTRUMENTO MENSURAdOR À PRÁtiCA CENTRAdA NA APRENDIZAGEM}

Se pedíssemos para alguns alunos descreverem uma situação avaliativa pela qual passaram, é provável que tivéssemos relatos de pavor e ansiedade extremos, que deixaram marcas em suas vidas difíceis de apagar. Não apenas os discentes teriam o que relatar; inclusive aqueles que avaliam, se questionados, possivelmente diriam que já foram submetidos a avaliações rijas, pontuais e focadas em resultados, que eventualmente neles causaram algum nível de sofrimento ou desconforto. Mesmo que grande parte dos docentes tenha passado por essa experiência, alguns destes ainda reproduzem o mesmo tipo de avaliação a que foram submetidos, de modo consciente ou não. Há aqueles, porém, que buscam novos conhecimentos sobre essa prática, com a intenção de propor avaliações, cujo enfoque não seja o de 
simplesmente mensurar a capacidade discente de mimetizar conteúdos postos, mas a de consistir em uma prática cotidiana propiciadora de reflexão e de melhorias no ensino e na aprendizagem.

Compreendemos que a avaliação utilizada apenas para verificar a aptidão (ou não) de alunos para prosseguimento nos estudos é inerente à educação tradicional, entendida, à guisa de Freire (2016), como educação bancária. Nessa concepção, o professor transfere conhecimentos ao aluno (mero receptor), do qual se cobra, no momento da avaliação, uma devolução idêntica ao que lhe foi transferido. Em tempo restrito, o receptor testado deve provar sua capacidade de guardar o objeto de depósito e na avaliação (prova/teste) devolvê-lo no mesmo estado ao depositante, que quantifica a aptidão de guardar. De acordo com Abramowicz (1995), a ideia de mensurar ou testar se vincula desde o princípio à avaliação da aprendizagem, vista em sua dimensão controladora, que foi acentuada nas primeiras décadas do século XX e deu à avaliação função instrumental, baseada em princípios positivistas. Com isso, passa a exercer o controle da aprendizagem e do próprio currículo escolar.

Conforme Méndez (2002), a avaliação vista como uma atividade natural tem o propósito de conhecer e se transforma em atividade formativa quando se baseia na reflexão. Contudo, o autor explica que, ao assumir o desígnio de qualificar, passa a ser uma atividade artificial, prática pedagógica comum criada por conveniência social para justificar a exclusão escolar, portanto, classificatória e seletiva. Nesse sentido, torna-se "um instrumento autoritário e frenador do desenvolvimento de todos os que passaram pelo ritual escolar, possibilitando a uns o acesso e o aprofundamento do saber, a outros a estagnação ou a evasão dos meios do saber. Mantém-se assim a distribuição social.” (LUCKESI, 2011, p.37).

À luz de Luckesi (2011), ao assumir um caráter classificatório, a avaliação não contribui para a promoção da aprendizagem efetiva dos alunos, pois limita-se a um momento pontual, não se atenta às individualidades e foca-se no resultado. Nessa acepção, a prática avaliativa assume os propósitos de corrigir, quantificar, classificar, selecionar e punir, sem estar vinculada à melhoria do processo formativo. (MÉNDEZ, 2002). Trata-se de prática autoritária considerada um instrumento disciplinador de condutas cognitivas e sociais e que vê no erro uma fonte de castigo. (LUCKESI, 2011).

Ao adotar uma avaliação desse tipo, o professor assume, usualmente, uma posição antagônica à do aluno, pois a utiliza como instrumento para manutenção de sua hegemonia em sala. Talvez isso explique alguns sentimentos do aluno, como: aversão ao docente (e à 
disciplina), medo e baixa autoestima. Abramowicz (1995) nos aponta possíveis motivos para tais sensações em face da avaliação, ao alegar que ela se manifesta, desde os primórdios, como um efetivo instrumento de controle educacional e evidencia uma relação autoritária, na qual os estudantes estão na condição de sujeitos apassivados e os docentes, de detentores do saber e do poder.

Esse tipo de avaliação constitui-se um instrumento estático do processo educativo, em nada contribuindo com o avanço e o desenvolvimento do aluno e do professor, pois visa apenas classificar, sem conduzir a uma tomada de decisão diante do que se está avaliando. (LUCKESI, 2011). Tem por foco não a aprendizagem efetiva e o protagonismo dos educandos, mas o controle e a obtenção de resultados quantificáveis. Ao se submeterem a um modelo avaliativo classificatório, os alunos que não conseguem bons resultados tendem a ser estigmatizados e responsabilizados por seu "fracasso" escolar. E, talvez, para se livrarem disso, muitos deles recorrem a subterfúgios como a utilização da cola.

Embora seja uma prática condenável, Gatti (2003) adverte que as razões que levam alguns discentes a colar na avaliação merecem análise do professor. Sem prejuízo ao tratamento repreensivo a ser conferido à conduta, a autora recomenda que ele tente compreender os motivos que levam alguns de seus alunos a utilizarem a cola nos momentos avaliativos e busque desenvolver ações específicas para minimizar o problema $^{1}$. Para tanto, parece necessário que o docente reflita sobre suas práticas avaliativas, averiguando se estão, de fato, focadas na aprendizagem significativa dos educandos e se assim estão sendo percebidas por eles. Nesse sentido, Gatti (2003) orienta-o a estabelecer uma relação dialógica com o aluno e a investigar as causas de seu sofrimento às vésperas e na hora da avaliação, demonstrando que ambos (aluno e professor) se envolvem no mesmo processo, de tal forma que o problema de aprendizagem de um é o problema de ensino do outro.

Ao tratar da avaliação no ensino superior, Gil (2018) destaca algumas acusações a ela atribuídas, sobretudo quando ocorre na forma de provas e exames. Dentre essas acusações, o autor ressalta que a avaliação tradicional pode incentivar a fraude (cola), além de: causar

\footnotetext{
${ }^{1}$ Embora o ato de colar consista em uma fraude, não podemos ignorar a capacidade de síntese que o aluno pode desenvolver ao elaborar sua cola. Portanto, é possível que, com planejamento, o professor a utilize como um recurso de ensino e aprendizagem, material de consulta para algumas de suas avaliações e, talvez, uma de suas formas. Com fulcro em Urbanski (2012), a cola pode ser uma estratégia de aprendizagem para sumarizar conteúdos. Mas, para ter caráter educativo, Hadji (1994) adverte que o docente precisa estabelecer previamente com os alunos regras e objetivos claros para seu uso educativo.
} 
estresse e ansiedade; conduzir a injustiças; privilegiar o controle do conteúdo em detrimento da aprendizagem efetiva; favorecer o imobilismo social; ter questionável validade; desencorajar os juízos pessoais; recompensar aprendizagens efêmeras; obstar o desenvolvimento dos discentes; e dificultar a prática de uma pedagogia da descoberta. (GIL, 2018).

Moretto (2008) assinala que a avaliação pode trazer angústia não somente aos estudantes, mas também a muitos docentes, ao se sentirem incapazes de torná-la prática educativa contínua e efetiva. Frustrados e inseguros, passam a utilizá-la como um instrumento de repressão, com o propósito de controlar, premiar e punir. Contudo, é aos alunos que esse tipo de avaliação aflige mais intensamente, sendo considerada por muitos deles: a "“hora do acerto de contas', 'a hora da verdade', 'a hora de dizer ao professor o que ele quer que eu saiba', ‘a hora da tortura'”. (MORETTO, 2008, p.85-86). Torna-se, assim, um “toma-lá-dá-cá", que renega características como a criatividade e a interpretação, impedindo o desenvolvimento dos alunos.

Conforme Moraes (2008), muito se confunde o processo avaliativo com os instrumentos utilizados para fornecer dados sobre o desempenho dos alunos, sendo instigada a aprendizagem com vistas à obtenção de um resultado (atribuição de nota). Nesse sentido, percebe-se uma dificuldade de assimilar o significado do referido processo, visto que "na maioria das vezes, os professores não conseguem desconectar a avaliação dos atos de comprovação, punição, recompensa e cobrança" (MORAES, 2008, p.39). À luz de Bonesi e Souza (2006), essa dificuldade só poderá ser superada quando os docentes se convencerem que o propósito da avaliação não está na mera quantificação dos resultados obtidos por meio dos instrumentos avaliativos, mas na reflexão sobre os dados que estes fornecem para a melhoria do processo de aprendizagem dos alunos.

Embora ao longo de sua história a avaliação tenha sido predominantemente mensuradora, com fins, muitas vezes, nada democráticos de classificar, selecionar e excluir, à guisa de Méndez (2002) e dos argumentos até aqui expostos, julgamos ser um elemento indispensável para os processos de ensino e aprendizagem. No entanto, reiteramos a necessidade de ela assumir outros desígnios. Consoante Méndez (2002, p.82):

A avaliação deve constituir uma oportunidade real de demonstrar o que os sujeitos sabem e como o sabem. Somente assim o professor poderá detectar a consistência do saber adquirido e a solidez sobre a qual vai se constituindo seu conhecimento. Quando este se manifesta, o professor poderá intervir inteligentemente [...]. Evidenciar erros, e também penalizá-los, não serve para esses propósitos; [...] equivale a deter, e inclusive romper, a própria dinâmica do processo. 
O excerto nos possibilita inferir que, pela avaliação, o professor pode identificar quais saberes foram construídos pelos alunos em bases sólidas e de que forma o fizeram. A partir disso, pode intervir adequadamente, agindo com cautela para não os paralisar em sua busca pelo conhecimento. Mesmo que o discente tenha errado durante o processo, a intervenção corretiva deve ter o condão de valorizá-lo em sua busca e orientá-lo para o acerto, sem o intento de castigá-lo.

Na concepção de Hoffmann (2011), a correção punitiva não conduz o discente à reflexão sobre os modos de converter erros em acertos. A autora entende que correção deve ser propiciadora de aprendizagem, encorajadora e destituída de objetivos espúrios como colocar o aluno em seu lugar, estigmatizá-lo ou puni-lo. Nessa perspectiva de ação avaliativa, o professor reputa o erro como elemento construtivo, "o que significa considerar que o conhecimento produzido pelo educando, num dado momento de sua experiência de vida, é um conhecimento em processo de superação". (HOFFMANN, 2011, p. 56). Constituindo-se uma ação mediadora, a avaliação estaria desvinculada da concepção tradicional de verificar respostas certas ou erradas, pois, nessa concepção, o erro construtivo se torna um elemento necessário para o ensino e a aprendizagem (HOFFMANN, 2011). Nesse contexto, "o professor deve assumir a responsabilidade de refletir sobre toda a produção de conhecimento do aluno, promovendo o 'movimento', favorecendo a iniciativa e a curiosidade no perguntar e no responder e construindo novos saberes junto com os alunos" (HOFFMANN, 2011, p. 63).

De acordo com Gil (2018), a avaliação como ação mediadora possibilita, a partir da reflexão, o fornecimento de informações para subsidiar a intervenção docente e para adequar seus procedimentos tanto às necessidades discentes, quanto aos objetivos de aprendizagem. Por esse prisma, a prática avaliativa pode conduzir o educando a refletir sobre o que e como aprendeu, capacitando-o para fazer sua autoavaliação. (GIL, 2018). É, pois, a reflexão do aluno sobre os seus próprios modos de conhecer que tem o condão de levá-lo ao conhecimento metacognitivo ${ }^{2}$, definido por Andretta et al. (2010, p.08), como: "um conjunto de crenças pessoais sobre todos os possíveis aspectos da atividade cognitiva".

\footnotetext{
${ }^{2}$ Neves (2007) esclarece que os processos metacognitivos são envolvidos pela aprendizagem, pois transformam informações em conhecimento, por meio de estratégias de aprendizagem, como a monitoração, a autorregulação e a avaliação de um processo, cujo escopo é a solução de um problema. Com tais estratégias o aluno pode gerir seus processos de conhecimento, sem afastar a importância docente na orientação. (ANDRETTA et al. 2010).
} 
Portanto, a avaliação não pode ser vista como um elemento avulso do processo de ensino e de aprendizagem, utilizada de forma autoritária e classificatória. Assumindo-se prática dialógica e mediadora, requer a interação entre aluno e professor, a este cabendo instigar naquele a curiosidade, o desenvolvimento de sua autonomia e de seu espírito crítico, a fim de capacitá-lo para a solução de problemas diversos. Ela precisa ser dinâmica, abrangente e integrar e percorrer todas as etapas do processo formativo. Por envolver todo o processo de aprendizagem, possui caráter processual e, em um contexto moderno, pode ser de três tipos: diagnóstica, formativa e somativa (GIL, 2018).

A avaliação diagnóstica busca identificar as aptidões iniciais, as necessidades e os interesses dos discentes, dirigindo-se à definição dos conteúdos e estratégias de ensino adequadas para os alunos avaliados. (GIL, 2018). Essa dimensão tende a fornecer dados para a escolha de estratégias de ensino e de aprendizagem e não objetiva dispor os alunos em um ranking, mas verificar sua situação, para eventual intervenção docente. (LUCKESI, 2011).

Se a avaliação diagnóstica busca uma identificação inicial do conhecimento e interesses dos alunos, a dimensão formativa, segundo Gil (2018), ocorre ao longo da instrução (semestre ou ano letivo) e proporciona informações sobre o desenvolvimento do processo de ensino e aprendizagem, possibilitando ao professor o ajuste de tal processo às características dos alunos. Em suma, esse tipo de avaliação não tem por intuito selecionar ou rotular, mas permitir que docentes e discentes redefinam prioridades e ajustem estratégias, visto que "suas funções são orientar, apoiar, reforçar e corrigir" (GIL, 2018, p. 217).

Já a avaliação somativa é pontual e determina previamente o alcance de objetivos definidos para o final de um curso ou etapa, com função fulcral de conferir um título ou certificado (GIL, 2018). Consoante Romanowski e Wachowicz (2006), ela se fundamenta na averiguação do desempenho discente diante dos objetivos de ensino fixados no planejamento.

Ao trazermos à baila os três tipos de avaliação, não estamos dizendo que são excludentes entre si, ao contrário, elas apresentam funções distintas e podem ser utilizadas articuladamente no processo educativo, visando a melhoria do ensino e da aprendizagem.

Como prática contínua que atende a distintas e articuladas funções, compreendemos, à luz em Gil (2018), que a avaliação precisa se desenvolver em modalidades diversificadas, em vista dos diferentes objetivos de aprendizagem e preferências dos estudantes, e em clima favorável, a ser alcançado a partir da relação respeitosa e comprometida entre professor e aluno, 
da clareza dos objetivos que envolvem a prática avaliativa e da preparação intelectual e emocional dos alunos para os momentos avaliativos. Nas palavras de Luckesi (2013, n.p.),

[...] a avaliação, por si, é um ato acolhedor, integrativo, inclusivo. Para compreender isso, importa distinguir avaliação de julgamento. O julgamento é um ato que distingue o certo do errado, incluindo o primeiro e excluindo o segundo. A avaliação tem por base uma situação, para, então (e só então), ajuizar a sua qualidade, tendo em vista dar-lhe suporte de mudança, se necessário.

Com base nos autores citados neste tópico, entendemos possível minimizar os sentimentos de ansiedade e temor perante a avaliação, ao concebê-la não como instrumento de intimidação e ameaça, mas como um ato amoroso, inclusivo e comprometido com a aprendizagem.

\section{MATERIAIS E MÉTODOS}

Este artigo resulta de um estudo realizado na disciplina Processos de Avaliação do Mestrado Acadêmico em Ensino da Universidade do Vale do Taquari - UNIVATES, no ano de 2017, sob o viés da pesquisa qualitativa, cujo ponto de partida são questões ou enfoques de interesses amplos, definidos à medida que o estudo se desenvolve (GODOY, 1995).

Tal método "envolve a obtenção de dados descritivos sobre pessoas, lugares e processos interativos pelo contato direto do pesquisador com a situação estudada, procurando compreender os fenômenos segundo a perspectiva dos sujeitos, ou seja, dos participantes da situação em estudo" (GODOY, 1995, p. 58). Como o interesse investigativo tem foco no processo, objetiva-se apreender, sob a ótica dos participantes, como um dado fenômeno se revela nas práticas interativas cotidianas. (GODOY, 1995).

Consiste, ainda, em um estudo de caso, entendido por Fonseca (2002), como um estudo focado em uma entidade determinada: um programa, uma instituição, um sistema educativo, uma pessoa ou unidade social, por exemplo, sendo desenvolvido, neste artigo, com educadores atuantes em escolas do município de Barra do Garças-MT.

O instrumento utilizado para a coleta de dados foi a entrevista semiestruturada, que, à luz de Triviños (1987, p.146), “[...] parte de certos conhecimentos básicos apoiados em teorias e hipóteses, que interessam à pesquisa, e que, em seguida oferecem amplo campo de interrogativas, fruto de novas hipóteses que vão surgindo à medida que se recebem as respostas do informante". Foi proposto um roteiro com três questões básicas sobre o assunto, a saber: 1 . Por que a avaliação tem provocado ansiedade e temor nos alunos ao longo de suas trajetórias formativas escolares? 2. Como superar a ideia de avaliação como instrumento centrado em 
resultados e causadora de sofrimento nos estudantes? 3. Quais características a avaliação deve assumir para que se constitua elemento inerente ao processo de ensino e aprendizagem?

Essas questões foram respondidas por quatro educadores de Barra do Garças - MT, a saber: duas pedagogas, ambas professoras atuantes nos níveis de ensino fundamental e superior; uma técnica em assuntos educacionais com experiência docente, servidora do Instituto Federal de Mato Grosso - IFMT; e um acadêmico (formando) de licenciatura plena em Geografia da Universidade Federal de Mato Grosso - UFMT, que realizava estágio de regência em uma escola estadual do município. Todos eles assinaram um Termo de Livre Consentimento Esclarecimento, autorizando o uso de suas respostas para a pesquisa, elaboração e publicação deste artigo. Para fins de identificação dos entrevistados, utilizamos designações alfanuméricas (P01 a P04).

Os dados emanados da entrevista foram tratados à luz da análise de conteúdo, conforme Bardin (2011), tendo o processo de análise percorrido as seguintes fases: a pré-análise; a exploração do material; e o tratamento dos resultados, a inferência e a interpretação.

\section{Resultados E Discussões}

As respostas dos participantes às questões da entrevista semiestruturada foram analisadas sob o prisma da pesquisa qualitativa, consistindo na articulação entre os recortes discursivos dos entrevistados e os pressupostos teóricos que baseiam o presente estudo. Foram tratadas sob a ótica da análise de conteúdo, fazendo emergir as três categorias temáticas abordadas a seguir. Partamos, então, para a exposição dos resultados desta análise.

\subsection{Motivos PARA SENTIR TEMOR E ANSIEDADE DIANTE DA AVALIAÇÃo}

A primeira categoria se refere aos possíveis motivos para que muitos alunos sentissem temor e ansiedade perante a avaliação. Na sequência discursiva a seguir, tais sentimentos são associados à forma como a avaliação foi elaborada. Vejamos:

[...] Muitos docentes ao focarem apenas no que ensinaram e no quanto ensinaram, não param para avaliar se o aluno aprendeu e o quanto ele aprendeu. Aí elaboram uma avaliação em cima de critérios que não foram estabelecidos em aulas, tornando a avaliação mais um acerto de contas do que um momento de reflexão e da ação do ensinar e do aprender. (P01).

Em sua resposta, P01 sugere que a avaliação pode causar sentimentos negativos, como o medo, a ansiedade e a aversão, ao focar no conteúdo transmitido e na quantidade de tópicos trabalhados pelo professor ao final de um período e não na aprendizagem dos estudantes. Acrescenta que, em sua opinião, isso explica a ênfase dada à capacidade mnemônica dos 
discentes avaliados, mensurada em um momento aparentemente apartado das práticas educativas.

Como alude P01, ao apresentar tal foco, a avaliação se constitui mais um acerto de contas do que uma oportunidade de estimular o aluno à aprendizagem. Reverbera, assim, Moretto (2008), que a considera um "toma-lá-dá-cá” se destituída de intenção educativa. Com respaldo em Freire (2016), inferimos que a concepção avaliativa a que se refere a entrevistada decorre de um ensino "bancário", que superestima a transmissão de conteúdo e despreza as singularidades dos alunos e sua efetiva aprendizagem. Nesse contexto, o resultado tem grande relevância, pois revela quanto do conteúdo transmitido foi assimilado.

O sentido de avaliação como acerto de contas se reitera na sequência discursiva de P02, que a considera inevitavelmente um meio de controle. Expressa que ela provoca medo e ansiedade porque:

[...] a avaliação, querendo ou não, ela é um meio de controle. A partir do momento que você tem uma avaliação que é de certa forma bem positivista, você acaba valorizando o que é tradicional, o que é memorizado, e isso nem sempre é interessante. Quando você fala a palavra prova ou atividade avaliativa, ela parece aliada a algum método de amedrontar os alunos. Então tem professores que utilizam a prova como um meio de descontar o que aconteceu em suas aulas. (P02)

No excerto em destaque, P02 diz que a avaliação "de certa forma bem positivista" valoriza o que é tradicional e memorizado. Conforme Goes e Brandalise (2015, p.34080), o pensamento positivista pode influenciar a educação em vários aspectos, por exemplo: “[...] na prática pedagógica desvinculada da prática social e, por consequência, na avaliação do processo de aprendizagem fundamentado principalmente na quantificação e na reprodução dos conteúdos transmitidos". Dessa forma, a associação feita pelo educador parece pertinente, pois uma avaliação assim engendrada se desvincula do contexto, não requer do aluno a reflexão, sequer que atribua sentidos ao que lhe está sendo ensinado, apenas que absorva e reproduza passivamente o conhecimento transmitido nas aulas.

Ao caracterizar a avaliação comumente praticada, P02 a associa ao propósito de se vingar, amedrontar e controlar comportamentos. Assim pensada, a avaliação escolar pode ser descrita como classificatória, distante das subjetividades dos alunos e meritocrática, isto é, utilizada com as finalidades de premiar e punir. Assume, nesse sentido, um caráter autoritário, coerente com o modelo liberal conservador de sociedade, tornando-se "um instrumento disciplinador não só de condutas cognitivas como também de condutas sociais, no contexto da escola" (LUCKESI, 2013, n.p.). 
Apresentando foco no resultado e não na aprendizagem, esse modelo avaliativo pode causar alguns sentimentos desagradáveis nos estudantes. Como argumenta Vasconcelos (1995, p.37), é possível que a avaliação escolar tradicional conduza os alunos a um nível assustador de pressão, "levando a distúrbios físicos e emocionais: mal-estar, dor de cabeça, 'branco', medo, angustia, insônia, ansiedade, decepção, introjeção de autoimagem negativa."

Igualmente, P03 opina que, ao assumir o propósito de rotular e punir, a avaliação pode provocar ansiedade nos estudantes, o que decorre do julgamento, da comparação e da exposição a que são submetidos. Em suas palavras:

A avaliação muitas vezes é usada para julgar, comparar um aluno com o outro, expor a criança, comparando-o com o outro e ninguém gosta de ser comparado ou de ser julgado e essa ansiedade [...] vem de ameaça. Por exemplo, a sala tá (sic) o maior caos, uma total falta de domínio dos alunos, aí (sic) o professor começa a ameaçar: se vocês não ficarem quietos, isso vai ser questão de prova [ou] menos um ponto na prova. O professor tenta ter domínio ameaçando com a avaliação. O que ele coloca [como regra] se não acontecer vai ser [cobrado] na avaliação. (P03)

A educadora acrescenta que a avaliação gera ansiedade, quando o comportamento dos alunos é usado pelo docente para culpá-los pela obtenção de notas baixas. Isso se evidencia ao dizer: "Se eu dou uma prova e percebo que noventa por cento da sala não conseguiu tirar nota, não fez nada na prova, aí eu culpo: ‘Ah, mas essa sala, essa turma é muito difícil, não tem jeito' e coloco a culpa no aluno, mas na verdade [...] a culpa foi (sic) na aula que eu ministrei”. (P03). Notamos, a partir do excerto, que, para a professora, a avaliação deveria servir à reflexão do docente sobre sua prática, o que, de acordo com a entrevistada, nem sempre ocorre.

Além disso, P03 afirma que a ação avaliativa pode ser utilizada pelo professor para ameaçar seus alunos e exercer controle sobre sua aprendizagem e seu comportamento, mas que, ao fazer isso, ele se esquece que "o resultado da avaliação reflete o que foi a sua aula, como foi, como que as crianças receberam seu conteúdo". Assim, entende que, além de traduzir como o docente está atuando em sala, o resultado revela como seus alunos receberam o conteúdo ministrado, o que nos parece decorrer de uma concepção tradicional ainda presente em sua forma de conceber a prática avaliativa. De acordo com Bonesi e Souza (2006, p.151), essa noção de avaliar com a finalidade de constatar a recepção do conteúdo subsiste nas práticas de muitos docentes. In verbis:

Os professores apresentam diferentes concepções a respeito de avaliação, entretanto prevalece, entre eles, uma compreensão de avaliação mais centrada nos resultados e nas constatações do que nos processos de aprendizagem e na análise dos percursos, vivenciados pelos atores que compartilham do espaço da sala de aula. 
Verificamos também que a concepção de avaliação focada nos resultados pode ser identificada nos motivos apontados no recorte discursivo a seguir:

Eu acho que vários motivos podem levar a esse temor com relação à avaliação, entre eles: a competitividade que essas avaliações quantitativas causam; se você [o aluno] tiver em um momento ruim ou não conseguir naquele momento ou se é uma pessoa que fica nervosa diante de situações de avaliação; [...] a avaliação desprendida do contexto, das discussões nas aulas. [...]; Se a avaliação tem fim em si mesma, ela não está avaliando o processo ou permitindo que [o professor] faça uma reflexão sobre a sua metodologia, sobre o processo de ensino e aprendizagem; ela está avaliando apenas o aluno que não conseguiu [se sair bem]; ele vai ser punido com a nota baixa e, se não se recuperar, vai ser punido com a reprovação. [...] Talvez isso cause grande temor, porque a consequência pode ser essa: pode ser que a pessoa não consiga se sair bem em uma prova, embora ela tenha compreendido o conteúdo. (P04).

No excerto, P04 destaca dentre as causas para o temor diante de momentos avaliativos: a competitividade oriunda da quantificação de desempenhos, a avaliação com fim em si mesma, a desconsideração das singularidades e de fatores externos que afetam o educando na hora da avaliação, a possível falta de correspondência entre sua aprendizagem e o resultado por ele obtido, bem como o caráter punitivo atribuído à nota baixa e à reprovação.

A resposta de P04 denuncia, ainda, que a finalidade da recuperação continua associada muito mais à obtenção de nota do que à melhoria da aprendizagem do aluno, sendo também vista como um momento apartado do processo educativo. Essa compreensão pode explicar, em certa medida, por que alguns discentes tentam burlar o sistema de avaliação usando o artifício da cola. Não lhes parece relevante os caminhos que os levam à aprendizagem, mas os resultados numericamente expressos que lhes são atribuídos ao final de cada etapa de sua formação escolar.

\subsection{MODOS DE SUPERAÇÃO DO MODELO AVALIATIVO CENTRADO EM RESULTADOS}

Parece pacífico, entre os entrevistados, o entendimento de que o modelo avaliativo focado em resultados precisa ser superado, o que requer do docente reflexão e ação sobre suas práticas. As respostas descritas e analisadas a seguir tratam dos modos como os participantes consideram possível que a avaliação supere esse modelo e deixe de causar sofrimento nos estudantes, tornando-se prática condutora de aprendizagem.

$\mathrm{Na}$ visão de P01, para que a avaliação deixe de focar no resultado e de provocar sofrimento nos alunos, o professor deve torná-la "um momento de reflexão e da ação do ensinar e do aprender, utilizando-se de critérios claros e estabelecidos em aula", constituindo-se, assim, uma prática educativa centrada na aprendizagem. Com base em Gil (2018), a avaliação mencionada pela educadora, ao conduzir o aluno à reflexão sobre seu processo de 
aprendizagem, instiga-o a fazer sua autoavaliação. Ao realizá-la, o discente pode entender as próprias formas de chegar ao conhecimento de um assunto. (ANDRETTA et al., 2010).

Ainda sob a ótica de P01, a reflexão e a ação devem ser incitadas principalmente pelo professor, cabendo a ele elaborar e propiciar aos discentes avaliações e estratégias que os levem a situações diferentes de aprendizagem, dadas as suas singularidades. Acrescenta que os docentes necessitam refletir sobre suas práticas, sendo a avaliação um dos elementos que subsidiam a reflexão, permitindo-lhes intervir com precisão no processo de aprendizagem de seus alunos. Conforme Bonesi e Souza (2006, p. 140):

No contexto escolar, no interior da sala de aula, a avaliação precisa estar a serviço da aprendizagem dos alunos - e não de sua eliminação efetivando-se, consequentemente, em uma perspectiva diagnóstico-formativa e, portanto, voltada para a compreensão do estágio de desenvolvimento e da etapa de aprendizagem em que se encontra o aluno, para melhor orientar o processo de ensino.

Sob essa perspectiva, a avaliação deve ocorrer de modo contínuo, ter foco na aprendizagem efetiva, autônoma e crítica dos alunos e objetivos claros e correspondentes ao que foi estabelecido em sala, como observa P01. Consoante Bonesi e Souza (2006, p. 140),

[...] definir com clareza, no ato do planejamento de ensino, qual o padrão de qualidade que se espera do aluno, após uma determinada aprendizagem, evitaria situações arbitrárias, propiciaria uma relação mais sincera e cooperativa entre professor e aluno e permitiria decisões fundadas no real.

Nesse sentido, P02 igualmente postula uma avaliação contínua e não apartada das realidades, ao dizer que "a avaliação deve existir, mas [...] deve ser feita de uma maneira contínua, diária, porque aí você luta um pouco contra essa memorização apenas. Interessante que fosse uma atividade que levasse em conta bem mais do que está exposto nos livros didáticos." Para o educador, a avaliação é de incontestável importância, malgrado em algumas situações ocorra em momentos estanques e promova a seleção de alunos. Em sua resposta, considera necessário um esforço docente para torná-la muito mais do que um instrumento por meio do qual o aluno devolve o que memorizou dos livros, fazendo-a uma prática educativa que propicie a participação efetiva dos alunos e sirva a estes como estímulo à curiosidade e à reflexão diante de objetos de conhecimento.

Ao afirmar que o docente pode lutar "contra essa memorização apenas", quando fizer da avaliação uma prática contínua, o professor indagado não refuta a necessidade da memorização, porém sugere que ela é insuficiente para a aprendizagem. Assim, apesar de não menosprezar o valor dos conteúdos dos livros, P02 entende que o conhecimento não se estrutura 
somente pela sua memorização, mas, sobretudo, pela reflexão e pelos significados que os alunos constroem sobre esses conteúdos em sua prática cotidiana. Conforme Moretto (2008, p. 126):

A memorização certamente tem seu lugar no processo de aprendizagem, desde que seja acompanhada da compreensão do significado do objeto de conhecimento. O que a escola da linha tradicional explorou com mais ênfase foi a memorização em busca do acúmulo de informações, em grande parte sem muito significado para os alunos.

Além de julgar relevantes as características de continuidade da avaliação e o dever de não se restringir à memorização de conteúdos do livro didático para superação de um tipo de avaliação rijo, que gera ansiedade e medo, P03 recomenda ao docente "avaliar sem parecer que está avaliando". Explica que, ao iniciar um novo conteúdo, pode-se iniciar pela avaliação diagnóstica, buscando identificar os conhecimentos prévios de seus alunos oriundos de outros espaços sociais. Portanto, "a avaliação tem início na hora que você começa a ministrar o conteúdo, o que exige do professor uma maior responsabilidade. [...] A avaliação diagnóstica é válida? É válida. Mas não pode ser só diagnóstica.” (P03).

Para P03, a função da avaliação não se encerra no simples ato de diagnosticar a situação cognitiva do aluno, mas serve para orientá-la sobre como foi seu trabalho e como pode intervir para alavancar a aprendizagem do discente. Lembrando que o "diagnóstico tem por objetivo aquilatar coisas, atos, situações, pessoas, tendo em vista tomar decisões no sentido de criar condições para a obtenção de uma maior satisfatoriedade que se esteja buscando ou construindo.” (LUCKESI, 2013, n.p.). Como sopesam Bonesi e Souza (2006, p.151), a avaliação diagnóstica deve vir "necessariamente, acompanhada de uma intervenção diferenciada".

Se a avaliação não for além do diagnóstico, torna-se prática autoritária e classificatória, pois se importa somente com os resultados, servindo para ratificar e perpetuar a situação do aluno. P04 pondera que "ela deve acima de tudo avaliar o processo de ensino e aprendizagem [...] se a avaliação tem fim em si, ela vai terminar ali. E o professor vai usá-la como um instrumento de punição ou de premiação." (P04). Consoante Luckesi (2013, n.p.) "importa estarmos cientes de que a avaliação educacional, em geral, e a avaliação da aprendizagem escolar, em particular, são meios e não fins em si mesmas, estando assim delimitadas pela teoria e prática que as circunstancializam”. Na opinião do autor, ao estar a serviço de uma pedagogia dominante, que serve a um modelo social dominante (modelo social liberal conservador), assume-se obrigatoriamente autoritária, utilizada como instrumento que classifica, rotula, premia ou pune, sem promover uma mudança na situação de quem é avaliado. 
Com base na resposta de P04, a avaliação com um fim em si mesma não permite uma intervenção docente a partir das informações geradas por ela, razão pela qual torna-se um mero instrumento para a devolução do que foi transmitido aos estudantes nas aulas. P04, dando continuidade à sua resposta, afirma que os alunos que comumente apresentam "maior dificuldade" em aprender continuam na mesma situação e, obviamente, não obtêm êxito nas provas, a menos que recorram a subterfúgios, como as colas.

A avaliação descrita por P04 parece ocorrer no contexto da avaliação tradicional, estando a noção de êxito, nesse caso, associada a padrões preestabelecidos quantificáveis (notas), que assumem maior relevância que a própria aprendizagem do aluno. Essa concepção é característica do sistema clássico de avaliação, que "favorece uma relação utilitarista com o saber. Os alunos trabalham 'pela nota': todas as tentativas de implantação de novas pedagogias se chocam com esse minimalismo". (PERRENOUD, 1999, p.66, grifo do autor). Nessa perspectiva, ela não auxilia o professor para uma intervenção consciente, já que, como a educadora revela, os alunos "com dificuldade" não melhoram sua situação. Portanto, entendemos, com base em Hoffmann (2011), que a prática avaliativa necessita ser repensada, inserindo-se no processo educativo como um instrumento para a reflexão e a ação.

Diante do exposto, intuímos que, para superar a ideia de avaliação escolar centrada em resultados, torna-se necessário entender que ela não deve se reduzir à relação utilitarista supracitada, sequer a um propósito classificatório, que permite ao docente apenas comparar os desempenhos de alunos sem, contudo, possibilitar-lhe a compreensão das causas mais profundas de suas dificuldades. Portanto, é fundamental que a avaliação se constitua um elemento inerente ao processo educativo, a partir do qual o professor seja capaz de refletir sobre seu trabalho e de orientar os alunos para sua aprendizagem efetiva, levando em conta seus diversos contextos de vida.

\subsection{Características de uma aValiação como prática eduCativa focada Na APRENDIZAGEM}

Para que a avaliação se constitua efetivamente uma prática educativa, necessitamos pensar em como ela deve ser vista. Destarte, esta categoria trata, sob o ponto de vista dos entrevistados, das características necessárias para que a avaliação seja entendida como uma prática inerente ao processo educativo e, sobretudo, centrada na aprendizagem.

P01 assevera que a avaliação deve ser "acima de tudo uma dinâmica mediadora de saberes. Enfim, um momento onde (sic) o aluno, enquanto ser capaz de reproduzir o 
conhecimento, signifique e o ressignifique pela sua aprendizagem". (P01). Por esse discurso, percebemos que a educadora se refere a uma avaliação que instiga o aluno a ir além da mera reprodução do conteúdo, o que só ocorre, à luz de Gil (2018), se ela for capaz de estimular-lhe a curiosidade e o questionamento.

Por sua vez, P02 esclarece que para ter o dinamismo aludido na resposta de P01, tornase necessário que a avaliação seja "contextualizada, respeitosa com a diversidade, diagnóstica e formativa". Deve ainda atentar para: "a vivência do aluno, sempre partindo do pressuposto de que ele já tenha um conhecimento que traz de algum lugar; e o docente deve apenas ajudá-lo a canalizar esse conhecimento para o que é cientificamente comprovado". (P02). Em nosso entendimento, a canalização do conhecimento prévio do estudante para o cientificamente comprovado, mencionada pelo educador, pode ser vista como parte do processo de construção de seu conhecimento, no qual se envolvem cooperativa e criticamente professor e aluno. Conhecimento este construído de forma significativa a partir do questionamento e da pesquisa.

Sob a perspectiva diagnóstica, colocada por P01 como necessária à prática avaliativa, esta pode ser entendida "como um ato amoroso, na medida em que a avaliação tem por objetivo diagnosticar e incluir o educando, pelos mais variados meios, no curso da aprendizagem satisfatória que integre todas as suas experiências de vida" (LUCKESI, 2013, n.p.). A professora reputa ainda a dimensão formativa como fundamental à avaliação, que apenas pode ser, por esse prisma, "cooperativa, negociada, matizada, centrada mais na tarefa e nos processos de aprendizagem do que na pessoa. Privada definitivamente do poder de classificar, de distinguir, de condenar globalmente alguém em função de seus desempenhos intelectuais." (PERRENOUD, 1999, 140).

Destarte, a avaliação pode ser pensada como um processo inclusivo, no qual o estudante tenha participação ativa e que esteja centrado em sua aprendizagem. Conforme P03, deve ser realizada de diferentes formas e vista como um elemento integrante do processo educativo, que “considera que o próprio aluno tenha construído sua nota, com um significado para si, parte da aprendizagem da criança”. (P03). Aponta que, para serem práticas educativas, as avaliações devem ser ainda: diversas, contínuas e inerentes ao processo de ensino e de aprendizagem. Contudo, quando afirma que o aluno construiu sua nota, a docente ainda parece dar grande enfoque aos resultados quantificáveis. Sobre isso, à luz de Luckesi (2010), ressaltamos que a nota se trata apenas do registro, que não pode se confundir com a qualidade da aprendizagem. 
Por seu turno, P04 pondera que a avaliação deve possibilitar: "a revisão, a reflexão sobre a prática, sobre o que e para que se está avaliando, observar as diferenças entre tempos de aprendizagem, entre contextos sociais, educacionais desses estudantes, além de [estar] inserida [n]os meus objetivos de ensino, de aprendizagem e nos objetivos institucionais". Essa compreensão de avaliação converge, de certo modo, com a ideia de Hoffmann (2011, p.15), segundo a qual ela "é essencial à educação, inerente e indissociável enquanto concebida como problematização, questionamento, reflexão sobre a ação". P02 coloca ainda a necessidade de ela estar coerente com os objetivos de ensino, aprendizagem e da própria escola, isso porque, em consonância com Libâneo (2017), não pode ser vista como uma etapa isolada, mas como elemento integrante do processo de ensino e aprendizagem.

Assim, assumindo as características mencionadas no presente tópico, a avaliação vincula-se aos propósitos de ensino e de aprendizagem, convertendo-se em uma prática educativa capaz de orientar os docentes para sua consciente intervenção no processo de aprendizagem dos alunos e, ao mesmo tempo, servindo para que estes se tornem participantes ativos do referido processo. Destarte, a ação avaliativa não mais será temida por estar centrada em resultados e cumprir estritamente os propósitos de classificar, premiar e/ou punir, mas, por estar focada na efetiva aprendizagem, será percebida como um elemento inclusivo, contextualizado, diagnóstico, formativo, e, portanto, fundamental para a construção do conhecimento e para o desenvolvimento dos alunos.

\section{CONSIDERaÇões Finais}

Neste artigo, identificamos, nas respostas dos entrevistados e nos pressupostos teóricos, alguns motivos que tornam a avaliação causadora de sofrimento aos alunos. Discutimos, ainda, os modos como podemos suplantar a avaliação centrada em resultados e torná-la uma prática educativa propiciadora de reflexão e de aprendizagem.

As respostas apresentadas pelos participantes deste estudo indicaram que quando a avaliação é tomada como um instrumento de controle, utilizada para punir ou premiar alunos, tende a provocar-lhes aversão, ansiedade e medo. Ademais, pudemos verificar que, embora o fator nota ainda seja relevante para o aluno e o professor, revestem-se de maior importância os aspectos qualitativos da avaliação, a partir dos quais podem ser propostas melhorias nos processos de ensino e de aprendizagem.

Em relação aos modos eficazes para a superação de um modelo tradicional de avaliação, os entrevistados ponderaram que a reflexão sobre suas práticas, a valorização dos 
conhecimentos prévios do aluno e a utilização de diferentes estratégias de aprendizagem constituem meios propiciadores de mudança da concepção avaliativa, o que torna o ensino mais democrático e a aprendizagem mais significativa e efetiva.

Para ser considerada prática educativa, os educadores afirmaram que a avaliação precisa ser: mediadora, participativa, inclusiva, contextualizada, dinâmica, diagnóstica, formativa e reflexiva. A partir dessas características, podemos dizer que a avaliação deve levar o professor à constante reflexão sobre suas práticas de ensino e sobre quais os recursos e métodos necessita utilizar para facilitar a aprendizagem de seus alunos, de acordo com suas peculiaridades.

Logo, a avaliação não pode servir de instrumento de coação ou de mera aferição de resultados, mas assumir um caráter plural, contemplando todas as dimensões necessárias para promover uma educação de qualidade aos alunos. Como elemento inerente ao processo educativo, precisa instigar os estudantes a buscarem soluções para problemas da sociedade, de forma crítica, reflexiva e autônoma. Isso contribui para se pensar a escola como um espaço de múltiplas aprendizagens e de produção de conhecimento.

\section{REFERÊNCIAS}

ABRAMOWICZ, Mere. Repensando a avaliação da aprendizagem no curso noturno. Ideias, São Paulo, v. 25, p. 38-46, 1995.

ANDRETTA, Ilana et al. Metacognição e Aprendizagem: como se relacionam? Psico, Porto Alegre, PUCRS, v. 41, n. 1, p.7-13, jan./mar. 2010. Disponível em: https://revistaseletronicas.pucrs.br/ojs/index.php/revistapsico/article/view/3879. Acesso em: 01 mar. 2017.

BARDIN, Laurence. Análise de conteúdo. São Paulo: Edições 70, 2011.

BONESI, Patrícia Góis; SOUZA, Nádia Aparecida de. Fatores que Dificultam a Transformação na Avaliação na Escola. Estudos em Avaliação Educacional, São Paulo, v. 17, n. 34, p. 129-144, maio/ago. 2006. DOI: https://doi.org/10.18222/eae173420062120. Disponível em: http://publicacoes.fcc.org.br/ojs/index.php/eae/article/view/2120/2077. Acesso em: 05 mar. 2017.

FONSECA, João José Saraiva da. Metodologia da pesquisa científica. Fortaleza: UEC, 2002.

FREIRE, Paulo. Pedagogia do Oprimido. 62. ed. Rio de Janeiro: Paz e Terra, 2016.

GATTI, Bernadete Angelina. O professor e a avaliação em sala de aula. Estudos em Avaliação Educacional, n. 27, p. 97-114, jan./jun. 2003. DOI:

https://doi.org/10.18222/eae02720032179. Disponível em:

https://www.fcc.org.br/pesquisa/publicacoes/eae/arquivos/1150/1150.pdf . Acesso em: 20 mar. 2017. 
GIL, Antonio Carlos. Didática do Ensino Superior. 2. ed. São Paulo: Atlas, 2018.

GODOY, Arilda Schmidt. Introdução à pesquisa qualitativa e suas possibilidades. Revista de Administração de Empresas, São Paulo, v. 35, n. 2, p. 57-63, 1995. Disponível em https://repositorio.unesp.br/bitstream/handle/11449/20594/S003475901995000200008.pdf? sequence=1\&isAllowed=y . Acesso em: 07 mar. 2017.

GOES. Graciete Tozetto; BRANDALISE, Mary Ângela Teixeira. Avaliação educacional: influências do positivismo, da fenomenologia e da teoria crítica. In: CONGRESSO NACIONAL DE EDUCAÇÃO - EDUCERE, 12, 2015, Curitiba. Anais [...] Curitiba: PUCPR, 2015, p. 34077-34091. Disponível em: http://educere.bruc.com.br/arquivo/pdf 2015/16635_7462.pdf. Acesso em: 20 mar. 2017.

HADJI, Charles. A avaliação regras do jogo: das intenções aos instrumentos. 4. ed. Portugal: Porto Editora, 1994.

HOFFMANN, Jussara Maria Lerch. Avaliação - mito e desafio: uma perspectiva construtivista. 41. ed. Porto Alegre: Mediação, 2011.

LIBÂNEO, José Carlos. Didática. São Paulo: Cortez, 2017. E-book (não paginado). Disponível em: https://books.google.com.br/books?id=q3MzDwAAQBAJ\&lpg=PP1\&hl=ptBR\&pg=PP1\#v=onepage\&q\&f=false. Acesso em: $01 \mathrm{fev} .2021$.

LUCKESI, Cipriano Carlos. Avaliação da aprendizagem componente do ato pedagógico. São Paulo: Cortez, 2011.

LUCKESI, Cipriano Carlos. Avaliação da aprendizagem e educação. 2010. Disponível em: http://www.gestaoescolar.diaadia.pr.gov.br/arquivos/File/sem_pedagogica/fev_2010/avaliaca oaprendizagemluckesi.pdf. Acesso em: 01 fev. 2021.

LUCKESI, Cipriano Carlos. Avaliação da aprendizagem escolar: estudos e proposições. 1.ed. São Paulo: Cortez, 2013. E-book (não paginado). Disponível em: https://books.google.com.br/books?id=uNTDAwAAQBAJ\&lpg=PP1\&hl=ptBR\&pg=PT6\#v=onepage \&q=circunstancializam\&f=false. Acesso em: $01 \mathrm{fev} .2021$.

MÉNDEZ, Juan Manoel Álvarez. A avaliação como atividade crítica. In: MÉNDEZ, Juan Manoel Álvarez. Avaliar para conhecer, examinar para excluir. Porto Alegre: Artmed Editora, 2002.

MORAES, Dirce Aparecida Foletto de. Avaliação formativa: re-significando a prova no cotidiano escolar. 2008. 146F. Dissertação (Mestrado em Educação) - Universidade Estadual de Londrina, Programa de Pós-graduação em Educação, Londrina, 2008. Disponível em: http://www.bibliotecadigital.uel.br/document/?code=vtls000146309. Acesso em: 19 fev. 2017.

MORETTO, Vasco Pedro. Prova um momento de estudo: não um acerto de contas. 8. ed. Rio de Janeiro: DP\&A, 2008.

NEVES, Dulce Amélia de Brito. Meta-aprendizagem e Ciência da Informação: uma reflexão sobre $o$ ato de aprender a aprender. Perspectivas em Ciência da Informação, v. 12, n. 3, p. 
116-128, dez. 2007. ISSN: 19815344. Disponível em:

http://portaldeperiodicos.eci.ufmg.br/index.php/pci/article/view/151. Acesso em: 01 mar. 2017.

PERRENOUD, Philippe. Avaliação: da excelência a regulação das aprendizagens. Porto Alegre: Artmed, 1999.

ROMANOWSKI, Joana Paulin; WACHOWICZ, Lílian Anna. Avaliação formativa no ensino superior que resistências manifestam os professores e os alunos? In: ANASTASIOU, Lea das Graças Camargos; ALVES, Leonir Pessate (Orgs). Processos de ensinagem na universidade: pressupostos para as estratégias de trabalho em aula. 6. ed. Joinvile: UNIVILLE, 2006. p. 121-139.

TRIVIÑOS, Augusto Nibaldo Silva. Introdução à pesquisa em ciências sociais: a pesquisa qualitativa em educação. São Paulo: Atlas, 1987.

URBANSKI, Bernadete. A utilização da "cola" como recurso de aprendizagem em uma prova escrita de matemática. PARANÁ/SEED. O professor PDE e os desafios da escola pública paranaense: Produção Didático-pedagógica. Londrina, 2012. Disponível em: http://www.diaadiaeducacao.pr.gov.br/portals/cadernospde/pdebusca/producoes_pde/2012/20 12 uel mat pdp bernadete urbanski.pdf. Acesso em: 07 fev. 2017.

VASCONCELOS, Celso dos Santos. Avaliação: concepção dialética -libertadora do processo de avaliação escolar. São Paulo: Libertad, 1995. 